Research Article

\title{
The Effect of Marital Status on Survival of Patients with Gastrointestinal Stromal Tumors: A SEER Database Analysis
}

\author{
Wei Song $\mathbb{D}^{1}$ and Chuan Tian $\mathbb{D}^{2}$ \\ ${ }^{1}$ Department of Intervention and Vascular Surgery, Affiliated Suzhou Hospital of Nanjing Medical University, \\ Suzhou Municipal Hospital, Suzhou Cancer Medical Center, Suzhou, China \\ ${ }^{2}$ Department of Nuclear Medicine, Guizhou Provincial People's Hospital, Guiyang, China
}

Correspondence should be addressed to Wei Song; songw2017@126.com

Received 26 June 2017; Accepted 10 December 2017; Published 1 February 2018

Academic Editor: Haruhiko Sugimura

Copyright (c) 2018 Wei Song and Chuan Tian. This is an open access article distributed under the Creative Commons Attribution License, which permits unrestricted use, distribution, and reproduction in any medium, provided the original work is properly cited.

\begin{abstract}
Background. Marital status has been reported to be a prognostic factor in multiple malignancies. However, its prognostic value on gastrointestinal stromal tumors (GISTs) have not yet been determined. The objective of the present analysis was to assess the effects of marital status on survival in patients with GISTs. Methods. The Surveillance, Epidemiology, and End Results (SEER) database was used to analyze 6195 patients who were diagnosed with GISTs from 2001 to 2014 . We also use Kaplan-Meier analysis and Cox regression to analyze the impact of marital status on cancer-specific survival (CSS). Results. Patients in the married group had more frequency in white people, more high/moderate grade tumors, and were more likely to receive surgery. Widowed patients had a higher proportion of women, a greater proportion of older patients ( $>60$ years), and more common site of the stomach. Multivariate analysis demonstrated that marital status was an independent prognostic factor for GISTs $(P<0.001)$. Married patients had better CSS than unmarried patients $(P<0.001)$. Subgroup analysis suggested that widowed patients had the lowest CSS compared with all other patients. Conclusions. Marital status is a prognostic factor for survival in patients with GISTs, and widowed patients are at greater risk of cancer-specific mortality.
\end{abstract}

\section{Introduction}

Gastrointestinal stromal tumors (GISTs) are the most common mesenchymal neoplasms arising from the gastrointestinal (GI) tract and account for $1-2 \%$ of all GI tumors [1]. They can occur anywhere along the alimentary tract, most commonly in the stomach with a frequency of approximately $60-70 \%$ [2]. They are thought to arise from the interstitial cells of Cajal (ICC), the pacemaker cells of the GI tract [3]. Radical resection with negative microscopic margins (R0) is the most effective therapy for the majority of patients $[4,5]$. Nevertheless, the postoperative recurrence rate for patients with localized GISTs can be 50\% [4, 6]. Presently, many tumor-specific parameters such as size, location, mitotic index, nuclear pleomorphism, and tumor necrosis are identified as prognostic factors for GISTs [5, 7-10]. However, only tumor size and mitotic index are the most widely used factors to predict the malignant potential of GISTs $[11,12]$. Therefore, it is vital to identify potential prognostic factors that predict prognosis and help clinicians implement better therapeutic strategies.

Several studies have suggested that marital status might serve as a promising prognostic factor for survival in multiple cancers [13-15]. It has been suggested that married individuals have longer overall and cancer-specific survival (CSS) than unmarried patients [16-18]. In a large study of multiple cancer sites, married patients were more likely to present with early-stage disease and more likely to receive definitive treatment than unmarried patients [19]. Being married has been shown to be positively associated with overall and cancer-related survival in multiple malignancies, such as hepatocellular carcinoma [15], gastric cancer [20], colorectal 
TABLE 1: Baseline demographic and tumor characteristics of patients in SEER database.

\begin{tabular}{|c|c|c|c|c|c|c|}
\hline Characteristic & $\begin{array}{c}\text { Total } \\
(n=6195) \\
N(\%)\end{array}$ & $\begin{array}{c}\text { Married } \\
(n=3787) \\
N(\%)\end{array}$ & $\begin{array}{c}\text { Widowed } \\
(n=758) \\
N(\%)\end{array}$ & $\begin{array}{c}\text { Single } \\
(n=1074) \\
N(\%)\end{array}$ & $\begin{array}{c}\text { Divorced/separated } \\
(n=576) \\
N(\%)\end{array}$ & $P$ value \\
\hline Sex & & & & & & $<0.001$ \\
\hline Male & 3240 & $2273(60.0)$ & $151(19.9)$ & $553(51.5)$ & $263(45.7)$ & \\
\hline Female & 2955 & $1514(40.0)$ & $607(80.1)$ & $521(48.5)$ & $313(54.3)$ & \\
\hline Age & & & & & & $<0.001$ \\
\hline$\leq 60$ & 2777 & $1710(45.2)$ & $54(7.1)$ & $708(65.9)$ & $305(53.0)$ & \\
\hline$>60$ & 3418 & 2077 (54.8) & 704 (92.9) & $366(34.1)$ & $271(47.0)$ & \\
\hline Race & & & & & & $<0.001$ \\
\hline White & 4237 & $2738(72.3)$ & $510(67.3)$ & $623(58.0)$ & $366(63.5)$ & \\
\hline Black & 1102 & $460(12.1)$ & 149 (19.7) & $332(30.9)$ & $161(28.0)$ & \\
\hline Others* & 856 & $589(15.5)$ & $99(13.1)$ & $119(11.0)$ & $49(8.5)$ & \\
\hline Tumor site & & & & & & $<0.001$ \\
\hline Stomach & 3794 & $2238(59.4)$ & $523(69.0)$ & $662(61.6)$ & $371(64.4)$ & \\
\hline Small intestine & 1858 & 1199 (31.8) & $183(24.1)$ & $317(29.5)$ & $159(27.6)$ & \\
\hline Rectum & 174 & $116(3.1)$ & $14(1.8)$ & $33(3.1)$ & $11(1.9)$ & \\
\hline Colon & 84 & $26(0.7)$ & $11(1.5)$ & $15(1.4)$ & $10(1.7)$ & \\
\hline Others & 285 & $186(4.9)$ & $27(3.6)$ & $47(4.4)$ & $25(4.3)$ & \\
\hline Tumor size & & & & & & 0.029 \\
\hline$\leq 2 \mathrm{~cm}$ & 412 & $268(7.1)$ & $47(6.2)$ & $66(6.1)$ & $31(5.4)$ & \\
\hline $2-5 \mathrm{~cm}$ & 1354 & $826(21.8)$ & $175(23.1)$ & $222(20.7)$ & $131(22.7)$ & \\
\hline $5-10 \mathrm{~cm}$ & 1579 & $980(25.9)$ & $189(24.9)$ & $270(25.1)$ & $140(24.3)$ & \\
\hline$>10 \mathrm{~cm}$ & 1236 & $740(19.5)$ & $123(16.2)$ & $253(23.6)$ & $120(20.8)$ & \\
\hline Unknown & 1614 & $973(25.7)$ & $224(29.6)$ & $263(24.5)$ & $154(26.7)$ & \\
\hline Grade & & & & & & 0.043 \\
\hline $\mathrm{I} / \mathrm{II}$ & 1209 & $767(20.3)$ & $133(17.5)$ & $199(18.5)$ & $110(19.1)$ & \\
\hline III/IV & 631 & $410(10.8)$ & $61(8.0)$ & $111(10.3)$ & $49(8.5)$ & \\
\hline Unknown & 4355 & $2610(68.9)$ & $564(74.4)$ & $764(71.1)$ & $417(72.4)$ & \\
\hline SEER stage & & & & & & 0.121 \\
\hline Localized & 3692 & $2306(60.9)$ & $458(60.4)$ & $599(55.8)$ & $329(57.1)$ & \\
\hline Regional & 826 & $499(13.2)$ & $91(12.0)$ & $159(14.8)$ & 77 (13.4) & \\
\hline Distant & 1234 & $719(19.0)$ & $149(19.7)$ & $237(22.1)$ & $129(22.4)$ & \\
\hline Unknown & 443 & $263(6.9)$ & $60(7.9)$ & $79(7.4)$ & $41(7.1)$ & \\
\hline Therapy & & & & & & $<0.001$ \\
\hline Surgery & 5055 & $3164(83.5)$ & $585(77.2)$ & $850(79.1)$ & $456(79.2)$ & \\
\hline No surgery & 2256 & $613(16.2)$ & $173(22.8)$ & $223(20.8)$ & $119(20.7)$ & \\
\hline Unknown & 36 & $10(0.3)$ & $0(0)$ & $1(0.1)$ & $1(0.2)$ & \\
\hline
\end{tabular}

* Others include American Indian/Alaska Native and Asian/Pacific Islander.

cancer [21], and pancreatic neuroendocrine tumors [22]. According to a larger population-based research on information from the SEER database, it is confirmed that unmarried individuals are at a higher risk of suffering from metastatic cancer, undertreatment, and even death causing from their cancer [19]. Nevertheless, the prognostic role of marital status in GISTs has not yet been assessed. Therefore, the primary objective of this study was to assess the prognostic effect of marital status in patients with GISTs. In the present study, we aimed to investigate the effect of marital status on CSS based on a large population data from the SEER database.

\section{Materials and Methods}

2.1. Data Source and Patient Selection. We used the SEER Program of the US National Cancer Institute (NCI) to identify 6195 patients who were diagnosed with GISTs from 2001 to 2014. The SEER Program captures approximately $97 \%$ of incident cancers, and the 17 SEER tumor registries encompass approximately $28 \%$ of the US population [23]. SEER Program collects information on cancer incidence, prevalence, survival, and mortality of patients with cancer.

Patients with GISTs were identified by the cancer staging scheme, version 0204 and histologic code (International 
Classification of Diseases for Oncology, Third Edition [ICD-O-3], code 8936). Patients were excluded if they had an unknown cause of death or survival month, age at diagnosis was less than 18 years, and a prior malignancy had been diagnosed.

This study was based on public data from the SEER database; we obtained permission to access research data files with the reference number 10091-Nov 2016. The data did not include the use of human subjects or personal identifying information. Thus, no informed consent was required for this part of the study.

2.2. Study Variables. The cohort was stratified based on marital status at the time of GIST diagnosis, with discrete strata for married and unmarried (widowed, single, separated, and divorced). Individuals in never married and unmarried or domestic partner were clustered together as a single group. Analyses were controlled for several patient variables, including demographics (sex, age, and race), tumor site (stomach, small intestine, rectum, colon, and others), tumor size $(\leq 2 \mathrm{~cm}, 2-5 \mathrm{~cm}, 5-10 \mathrm{~cm},>10 \mathrm{~cm}$, and unknown), SEER Stage (localized, regional, distant, and unknown), tumor grade (well-differentiated, moderately differentiated, poorly differentiated, undifferentiated, and not differentiated/ unknown), treatment (surgery, no surgery, and unknown), and marital status. The primary outcomes of interest in this study were 5-year CSS, which was calculated from the date of diagnosis to the date of cancer-specific death. Deaths attributed to GISTs were treated as events, while deaths from other causes were treated as censored observations.

2.3. Statistical Analyses. Baseline clinicopathological characteristics were analyzed with the chi-square test for categorical variables. Survival function estimation was performed with the Kaplan-Meier method and the resulting curves compared with the log-rank test. The hazard ratio (HR) for relationships between each variable and mortality was calculated using Cox proportional hazards multivariable regression. All $P$ values were two-sided, and $P$ values $<0.05$ were considered statistically significant. All statistical analyses were computed using SPSS version 23 (IBM Corporation, Armonk, NY, USA).

\section{Results}

3.1. Baseline Patient Characteristics. In totality, 6195 eligible GIST patients were recognized during the 13-year study period (between 2001 and 2014). Of these patients, 3240 were male and 2955 were female. In total, 3787 (61.1\%) were married, 2408 (38.9\%) were unmarried including 758 (12.2\%) widowed, 1074 (17.3\%) never married, and 576 (9.4\%) divorced/separated. Patients in the married group were more likely to be male $(60.0 \%)$, while widowed patients have the highest proportion $(80.1 \%)$ of female patients. Compared with unmarried patients, the married individuals had more frequency in white people, more high/moderate grade tumors, and were more likely to receive surgery. Patients in the widowed group had the higher proportion of elderly patients ( $>60$ years) and more common site of the stomach.

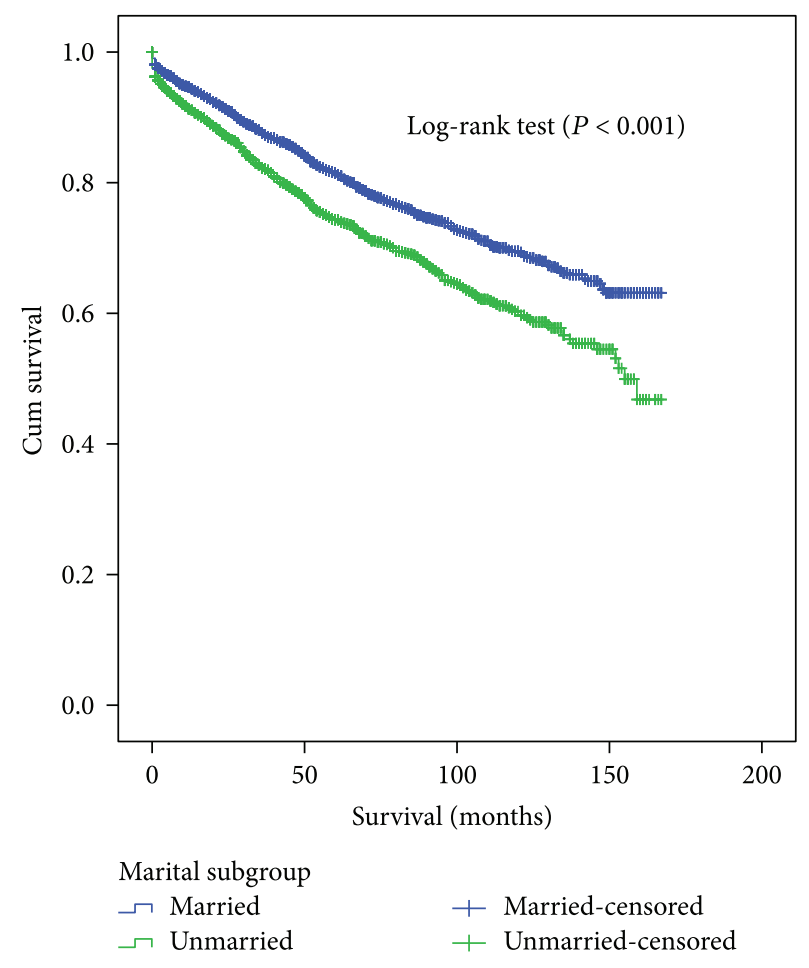

FIGURE 1: Survival curves in GIST patients between the married patients and the unmarried patients. $\chi^{2}=41.303, P<0.001$.

However, the proportion of married and widowed patients in localized disease was similar. All comparisons were statistically significant $(P<0.001)$. Table 1 provides patient demographics and pathological features.

3.2. Influence of Marital Status on CSS. The 5-year CSS was determined by univariate log-rank test. Patients in the married group had better 5-year CSS (81.5\%) than patients who were single $(75.8 \%)$, widowed $(69.4 \%)$, and divorced/separated (78.1\%) (Figures 1 and 2(a)). Additionally, male sex $(P<0.001)$, elderly patients $(P<0.001)$, black ethnicity $(P=0.021)$, colon GIST $(P<0.001)$, tumor size $>10 \mathrm{~cm} \quad(P<0.001)$, grade III or IV $(P<0.001)$, advanced SEER stage $(P<0.001)$, and no surgery patients $(P<0.001)$ were regarded as significant risk factors by univariate analysis (Table 2).

The variables which were significant in the univariate log-rank test were validated as independent prognostic factors by multivariate Cox regression analysis. As shown in Table 2, gender (female, hazard ratio (HR) $0.741,95 \%$ confidence interval (CI) $0.658-0.834$ ), age ( $>60$ years, HR 1.649 , 95\% CI 1.461-1.861), tumor site (colon, HR 1.916, 95\% CI 1.344-2.732; others, HR 1.388, 95\% CI 1.133-1.700), tumor size (>10 cm, HR 1.752, 95\% CI 1.181-2.599; unknown, HR 1.945 , 95\% CI 1.322-2.861), pathological grading (grade III/ IV, HR 2.965, 95\% CI 2.310-3.807; unknown, HR 1.547, 95\% CI 1.242-1.927), SEER stage (regional, HR 1.983, 95\% CI 1.675-2.348; distant, HR 2.952, 95\% CI 2.542-3.428; unknown, HR 1.594, 95\% CI 1.288-1.973), therapy (no surgery, HR 2.428, 95\% CI 2.121-2.779; unknown, HR 4.142, 95\% CI 1.703-10.075), and marital status (widowed, HR 

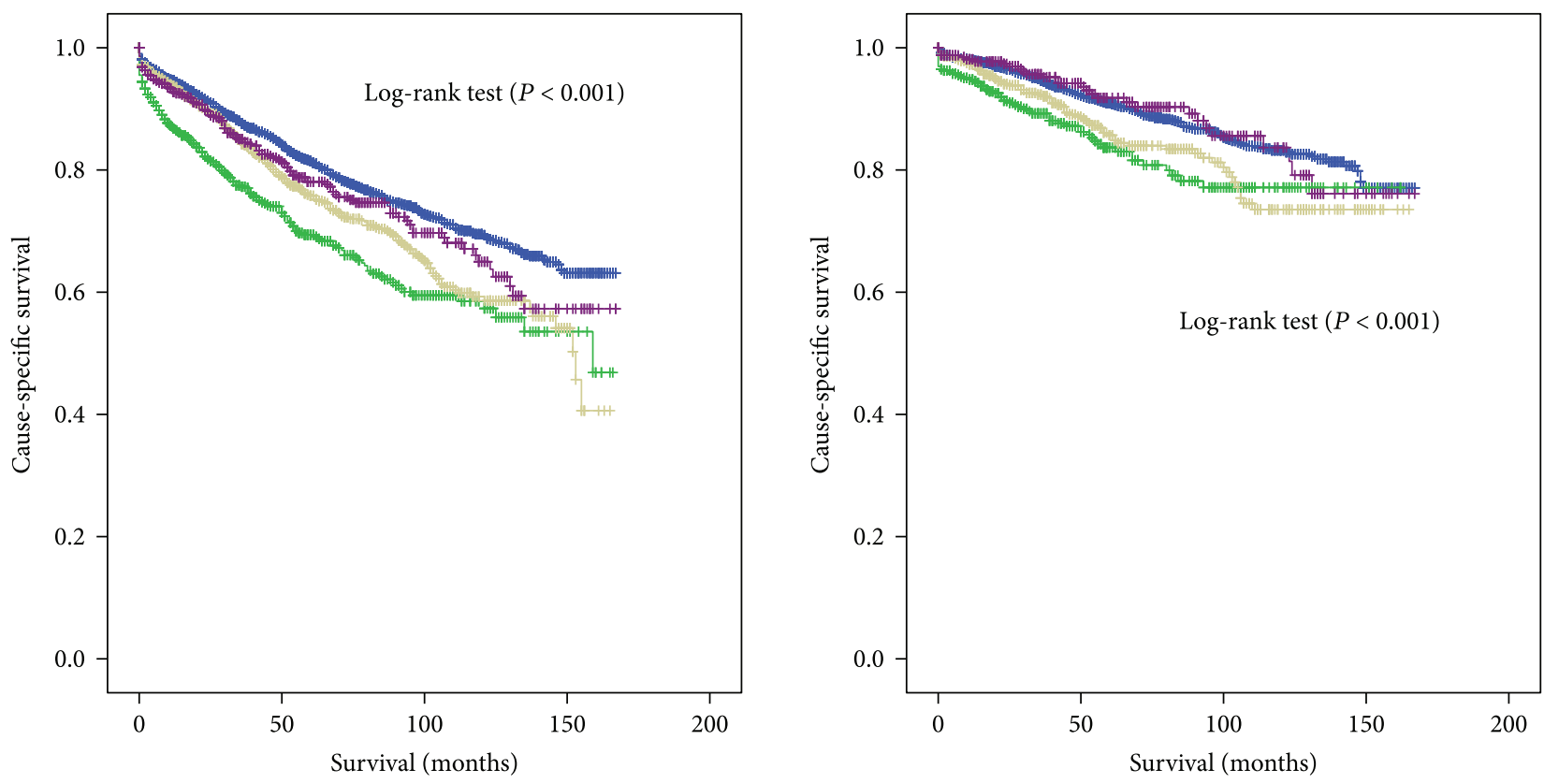

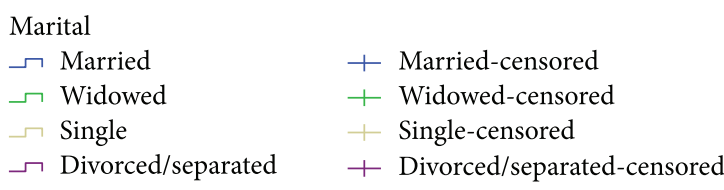

(a)

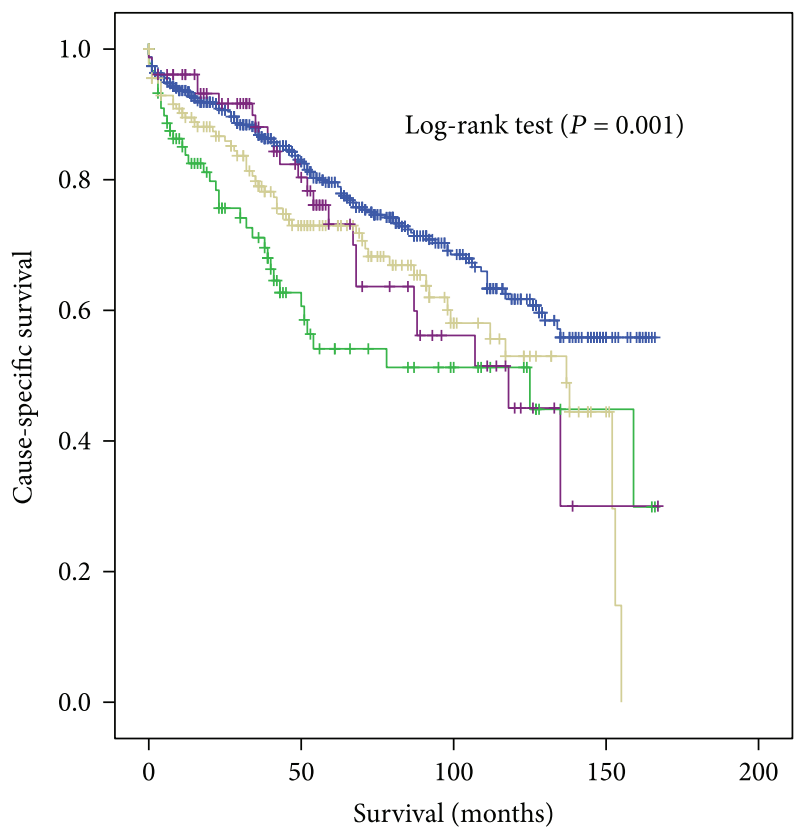

Marital

$$
\begin{array}{ll}
\neg \text { Married } & + \text { Married-censored } \\
\neg \text { Widowed } & + \text { Widowed-censored } \\
\neg \text { Single } & + \text { Single-censored } \\
\neg \text { Divorced/separated } & + \text { Divorced/separated-censored }
\end{array}
$$

(c)

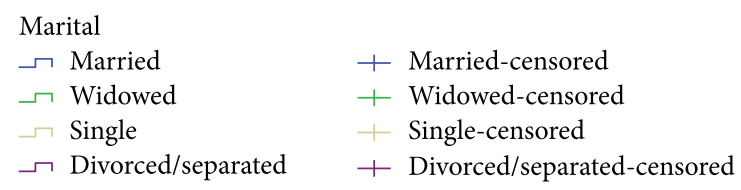

(b)

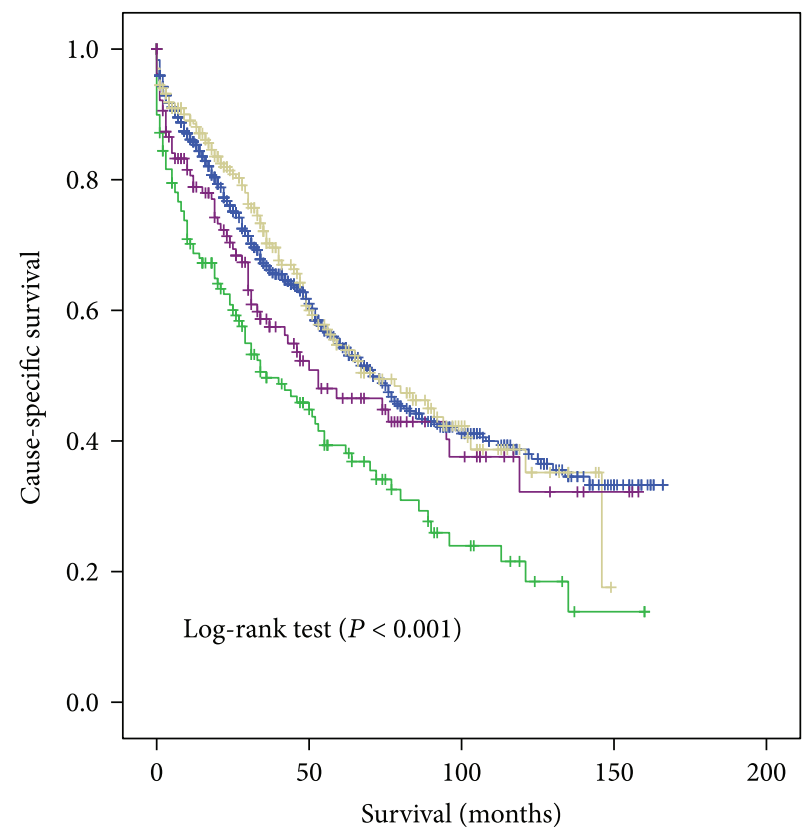

Marital

$$
\begin{array}{ll}
\neg \text { Married } & + \text { Married-censored } \\
\neg \text { Widowed } & + \text { Widowed-censored } \\
\neg \text { Single } & + \text { Single-censored } \\
\neg \text { Divorced/separated } & + \text { Divorced/separated-censored }
\end{array}
$$

(d)

FIgURE 2: Survival curves in GIST patients according to marital status. (a) All stage: $\chi^{2}=60.533, P<0.001$. (b) Localized: $\chi^{2}=22,360$, $P<0.001$. (c) Regional: $\chi^{2}=17.534, P=0.001$. (d) Distant: $\chi^{2}=24.437, P<0.001$. 
TABLE 2: Univariate and multivariate survival analysis for evaluating the influence of marital status on CSS in SEER database.

\begin{tabular}{|c|c|c|c|c|c|}
\hline \multirow[b]{2}{*}{ Variable } & \multirow[b]{2}{*}{ 5-year CCS } & \multicolumn{2}{|c|}{ Univariate analysis } & \multicolumn{2}{|c|}{ Multivariate analysis } \\
\hline & & Log-rank $\chi^{2}$ test & $P$ & $\mathrm{HR}(95 \% \mathrm{CI})$ & $P$ \\
\hline Sex & & 21.361 & $<0.001$ & & \\
\hline Male & $76.2 \%$ & & & Reference & \\
\hline Female & $81.7 \%$ & & & $0.741(0.658-0.834)$ & $<0.001$ \\
\hline Age & & 67.660 & $<0.001$ & & \\
\hline$\leq 60$ & $83.1 \%$ & & & Reference & \\
\hline$>60$ & $75.1 \%$ & & & $1.649(1.461-1.861)$ & $<0.001$ \\
\hline Race & & 7.697 & 0.021 & & \\
\hline White & $79.1 \%$ & & & Reference & \\
\hline Black & $76.6 \%$ & & & $0.968(0.835-1.122)$ & 0.666 \\
\hline Others* & $80.0 \%$ & & & $0.877(0.737-1.045)$ & 0.142 \\
\hline Tumor site & & 80.258 & $<0.001$ & & \\
\hline Stomach & $79.8 \%$ & & & Reference & \\
\hline Small intestine & $80.1 \%$ & & & $1.018(0.895-1.158)$ & 0.785 \\
\hline Rectum & $84.0 \%$ & & & $0.841(0.582-1.215)$ & 0.356 \\
\hline Colon & $56.3 \%$ & & & $1.916(1.344-2.732)$ & $<0.001$ \\
\hline Others & $61.2 \%$ & & & $1.388(1.133-1.700)$ & 0.002 \\
\hline Tumor size & & 282.519 & $<0.001$ & & \\
\hline$\leq 2 \mathrm{~cm}$ & $90.2 \%$ & & & Reference & \\
\hline$>2-5 \mathrm{~cm}$ & $92.8 \%$ & & & $0.714(0.466-1.094)$ & 0.122 \\
\hline$>5-10 \mathrm{~cm}$ & $83.5 \%$ & & & $1.256(0.846-1.866)$ & 0.259 \\
\hline$>10 \mathrm{~cm}$ & $70.8 \%$ & & & $1.752(1.181-2.599)$ & 0.005 \\
\hline Unknown & $68.7 \%$ & & & $1.945(1.322-2.861)$ & 0.001 \\
\hline Grade & & 197.472 & $<0.001$ & & \\
\hline I/II & $91.2 \%$ & & & Reference & \\
\hline III/IV & $62.0 \%$ & & & $2.965(2.310-3.807)$ & $<0.001$ \\
\hline Unknown & $78.2 \%$ & & & 1.547 (1.242-1.927) & $<0.001$ \\
\hline SEER stage & & 792.340 & $<0.001$ & & \\
\hline Localized & $89.4 \%$ & & & Reference & \\
\hline Regional & $75.2 \%$ & & & $1.983(1.675-2.348)$ & $<0.001$ \\
\hline Distant & $52.0 \%$ & & & $2.952(2.542-3.428)$ & $<0.001$ \\
\hline Unknown & $76.0 \%$ & & & $1.594(1.288-1.973)$ & $<0.001$ \\
\hline Therapy & & 6161.438 & $<0.001$ & & \\
\hline Surgery & $84.2 \%$ & & & Reference & \\
\hline No surgery & $52.8 \%$ & & & $2.428(2.121-2.779)$ & $<0.001$ \\
\hline Unknown & $40.0 \%$ & & & $4.142(1.703-10.075)$ & 0.002 \\
\hline Marital status & & 60.533 & $<0.001$ & & \\
\hline Married & $81.5 \%$ & & & Reference & \\
\hline Widowed & $69.4 \%$ & & & $1.674(1.411-1.986)$ & $<0.001$ \\
\hline Single & $75.8 \%$ & & & $1.377(1.183-1.602)$ & $<0.001$ \\
\hline Divorced/separated & $78.1 \%$ & & & $1.233(1.014-1.501)$ & 0.036 \\
\hline
\end{tabular}

*Others include American Indian/Alaska Native, Asian/Pacific Islander, and unknown. NI: not included in the multivariate survival analysis.

1.674, 95\%CI 1.411-1.986; single, HR 1.377, 95\%CI 1.1831.602; divorced/separated, HR 1.233, 95\% CI 1.014-1.501).

3.3. Subgroup Analysis by SEER Stage. We also analyzed the influence of marital status on CSS at each SEER stage. We had some interesting findings. First, marital status was an independent prognostic factor in each tumor stage both in the univariate and multivariate analysis $(P<0.001)$. Second, patients in the widowed group had the lowest survival rate in comparisons at all SEER stages. Compared with married patients, widowed patients had $7.6 \%$ reduction in 5 -year CSS at localized stage $(91.0 \%$ versus $83.7 \%, P<0.001)$, $25.5 \%$ reduction at regional stage $(79.6 \%$ versus $54.1 \%, P<$ $0.001)$, and $15.6 \%$ reduction at distant stage $(54.9 \%$ versus 
TABLE 3: Univariate and multivariate analysis of marital status on CSS based on different cancer stage.

\begin{tabular}{|c|c|c|c|c|c|}
\hline \multirow[b]{2}{*}{ Variable } & \multirow[b]{2}{*}{ 5-year CCS } & \multicolumn{2}{|c|}{ Univariate analysis } & \multicolumn{2}{|c|}{ Multivariate analysis } \\
\hline & & Log-rank $\chi^{2}$ test & $P$ & $\operatorname{HR}(95 \% \mathrm{CI})$ & $P$ \\
\hline \multicolumn{6}{|l|}{ SEER stage } \\
\hline Localized & & 22,360 & $<0.001$ & & \\
\hline Marital status & & & & & $<0.001$ \\
\hline Married & $91.0 \%$ & & & Reference & \\
\hline Widowed & $83.7 \%$ & & & $1.792(1.347-2.382)$ & $<0.001$ \\
\hline Single & $85.7 \%$ & & & $1.498(1.150-1.952)$ & 0.003 \\
\hline Divorced/separated & $91.8 \%$ & & & $0.964(0.654-1.420)$ & 0.852 \\
\hline Regional & & 17.534 & 0.001 & & \\
\hline Marital status & & & & & 0.001 \\
\hline Married & $79.6 \%$ & & & Reference & \\
\hline Widowed & $54.1 \%$ & & & $2.077(1.425-3.026)$ & $<0.001$ \\
\hline Single & $73.0 \%$ & & & $1.488(1.080-2.049)$ & 0.015 \\
\hline Divorced/separated & $73.2 \%$ & & & $1.362(0.872-2.127)$ & 0.174 \\
\hline Distant & & 24.437 & $<0.001$ & & \\
\hline Marital status & & & & & $<0.001$ \\
\hline Married & $54.9 \%$ & & & Reference & \\
\hline Widowed & $39.3 \%$ & & & $1.726(1.365-2.182)$ & $<0.001$ \\
\hline Single & $54.7 \%$ & & & $0.958(0.762-1.205)$ & 0.714 \\
\hline Divorced/separated & $46.5 \%$ & & & $1.216(0.922-1.605)$ & 0.166 \\
\hline
\end{tabular}

$39.3 \%, P<0.001)$. Third, there was no apparent difference between the married and divorced/separated patients in all stage (Table 3, Figures 2(b)-2(d)).

\section{Discussion}

To the best of our knowledge, this is the first study to date which comprehensively investigates the effect of marriage on CSS in GIST patients. Our study showed that married patients have a better CSS and lower mortality than those unmarried patients. In multivariable analyses, the beneficial effect for married patients lasted even after adjusting for sex, age, race, tumor site, tumor size, pathology grade, SEER stage, and therapy. Moreover, patients in the widowed group were more likely to suffer from survival disadvantages than other patients. In addition, subsequent subgroup analysis, based on SEER stage, validated the prognostic value of marital status in GISTs.

One hypothesis for the worse survival in unmarried patients is delayed diagnosis with advanced tumor stage $[19,24,25]$; however, our study showed that the percentages of patients with all SEER stages were comparable among the four subgroups. Moreover, widowed patients have the highest percentage of localized stage $(60.4 \%)$ and the lowest 5-year CSS (69.4\%). Obviously, delayed diagnosis cannot explain the poor prognosis of widowed patients. The exact mechanisms underlying the prognostic impact of marital status in GISTs are unclear. Several biological, psychological, and social theories have been postulated to explain this phenomenon. It is well known that a diagnosis of cancer is psychologically distressing for most patients [26]. Single cancer patients may display more distress, depression, and anxiety than unmarried patients, since there is no spouse that the patient could share the emotional burden and afford sufficient social supports $[27,28]$. In addition, marital status may affect adherence to prescribed treatments. Compared with unmarried patients, married patients were more likely to comply with treatment and to seek treatment at more highly recognized centers, all of which may result in better cancer control $[29,30]$. Interestingly, we found that the married patients had the highest proportion of surgery $(83.5 \%)$, while the lowest proportion of surgery $(83.5 \%)$ is in the widowed group $(77.2 \%)$. Thus, the hypothesis of undertreatment for widowed patients might be supported by these findings.

Accumulating evidence suggested that the level of physiological stress and depression may affect cancer outcomes via different mechanisms. Decreased psychosocial support and psychological stress result in immune dysfunction and contribute to tumor progression and mortality [31-33]. Moreover, the lack of social support can reduce the activity of natural killer cells [34], and result in disorders of various endocrine hormones, such as cortisol and catecholamines $[31,33]$. Chronic stress may promote cortisol secretion $[35,36]$. Increased cortisol levels may downregulate the cortisol receptors in white blood cells, thus reducing antiinflammatory response and promoting cytokine-mediated inflammatory processes [37]. Several studies showed that cortisol and catecholamines could accelerate the growth and metastasis of malignant tumors via immunosuppressive actions [38-40]. Besides, cortisol patterns have been validated as a favorable prognostic factor in breast and lung cancers $[36,40]$. Additionally, depression and quality of life are associated with an increased production of VEGF, which 
may stimulate endothelial cell proliferation, migration, and proteolytic activity [41]. Burgess et al. found that depression and anxiety were associated with breast cancer recurrence [42]. Stress mediators produced in chronic stress could result in tumor metastasis through activation of specific signaling pathways and the tumor microenvironment [33].

Although the present study is based on a large population, some limitations need to be addressed. First, the SEER database only provides the marital status at diagnosis. However, the marital status of some patients may change during the therapeutic process, and these changes may have affected the outcomes. Second, the SEER database lacks details about the duration of the marriage, quality of the marriage, or length of being single, which might influence the prognosis of GIST patients. Marital distress has long-term immune consequences and increases the risk of various health problems [43]. Third, the SEER database did not provide some important information regarding adjuvant therapy, comorbidities, recurrence, or income/insurance status, which could not be adjusted by our analyses.

Despite these limitations, this study was based on a large population and multiple centers and is therefore reliable and persuasive. Our findings demonstrated that marital status is an independent prognostic factor for survival in patients with GISTs. Furthermore, unmarried GIST patients, especially widowed patients, are at greater risk for cancer-specific mortality. The main reasons for poor survival in unmarried patients can be explained hypothetically by social support and psychological factors. Therefore, more social supports should be provided for unmarried patients, especially the widowed patients.

\section{Disclosure}

The interpretation and reporting of these data are the sole responsibility of the authors.

\section{Conflicts of Interest}

The authors declare no conflicts of interest.

\section{Authors' Contributions}

Wei Song and Chuan Tian conceived and designed the study, searched the databases and collected the data, analyzed and interpreted the data, wrote the manuscript, and reviewed the final manuscript.

\section{Acknowledgments}

The authors acknowledge the efforts of the Surveillance, Epidemiology, and End Results (SEER) Program tumor registries in the creation of the SEER database.

\section{References}

[1] C. L. Corless, "Gastrointestinal stromal tumors: what do we know now?," Modern Pathology, vol. 27, pp. S1-S16, 2014.

[2] H. Joensuu, "Gastrointestinal stromal tumor (GIST)," Annals of Oncology, vol. 17, Supplement 10, pp. x280-x286, 2006.
[3] M. Miettinen and J. Lasota, "Gastrointestinal stromal tumors," Gastroenterology Clinics of North America, vol. 42, no. 2, pp. 399-415, 2013.

[4] Y. X. Koh, A. Y. Chok, H. L. Zheng et al., "A systematic review and meta-analysis comparing laparoscopic versus open gastric resections for gastrointestinal stromal tumors of the stomach," Annals of Surgical Oncology, vol. 20, no. 11, pp. 3549-3560, 2013.

[5] B. K. Goh, P. K. Chow, W. M. Yap et al., "Which is the optimal risk stratification system for surgically treated localized primary GIST? Comparison of three contemporary prognostic criteria in 171 tumors and a proposal for a modified Armed Forces Institute of Pathology risk criteria," Annals of Surgical Oncology, vol. 15, no. 8, pp. 2153-2163, 2008.

[6] Z. Jiang, J. Zhang, Z. Li, Y. Liu, D. Wang, and G. Han, “A metaanalysis of prognostic value of KIT mutation status in gastrointestinal stromal tumors," OncoTargets and Therapy, vol. 9, pp. 3387-3398, 2016.

[7] H. Joensuu, P. Hohenberger, and C. L. Corless, "Gastrointestinal stromal tumour," The Lancet, vol. 382, no. 9896, pp. 973983, 2013.

[8] P. Rutkowski, Z. I. Nowecki, W. Michej et al., "Risk criteria and prognostic factors for predicting recurrences after resection of primary gastrointestinal stromal tumor," Annals of Surgical Oncology, vol. 14, no. 7, pp. 2018-2027, 2007.

[9] H. Joensuu, "Risk stratification of patients diagnosed with gastrointestinal stromal tumor," Human Pathology, vol. 39, no. 10, pp. 1411-1419, 2008.

[10] J. S. Gold, M. Gonen, A. Gutierrez et al., "Development and validation of a prognostic nomogram for recurrencefree survival after complete surgical resection of localised primary gastrointestinal stromal tumour: a retrospective analysis," The Lancet Oncology, vol. 10, no. 11, pp. 10451052, 2009.

[11] R. P. Dematteo, J. S. Gold, L. Saran et al., "Tumor mitotic rate, size, and location independently predict recurrence after resection of primary gastrointestinal stromal tumor (GIST)," Cancer, vol. 112, no. 3, pp. 608-615, 2008.

[12] A. Y. Chok, B. K. Goh, Y. X. Koh et al., "Validation of the MSKCC gastrointestinal stromal tumor nomogram and comparison with other prognostication systems: single-institution experience with 289 patients," Annals of Surgical Oncology, vol. 22, no. 11, pp. 3597-3605, 2015.

[13] D. S. Bai, P. Chen, J. J. Qian, S. J. Jin, and G. Q. Jiang, "Effect of marital status on the survival of patients with gallbladder cancer treated with surgical resection: a population-based study," Oncotarget, vol. 8, pp. 26404-26413, 2017.

[14] O. S. Adekolujo, S. Tadisina, U. Koduru, J. Gernand, S. J. Smith, and R. R. Kakarala, "Impact of marital status on tumor stage at diagnosis and on survival in male breast cancer," American Journal of Men's Health, vol. 11, no. 4, pp. 11901199, 2016.

[15] W. Zhang, X. Wang, R. Huang et al., "Prognostic value of marital status on stage at diagnosis in hepatocellular carcinoma," Scientific Reports, vol. 7, article 41695, 2017.

[16] R. M. Kaplan and R. G. Kronick, "Marital status and longevity in the United States population," Journal of Epidemiology and Community Health, vol. 60, no. 9, pp. 760-765, 2006.

[17] H. YR and N. Goldman, "Mortality differentials by marital status: an international comparison," Demography, vol. 27, no. 2, pp. 233-250, 1990. 
[18] C. Wu, P. Chen, J. J. Qian et al., "Effect of marital status on the survival of patients with hepatocellular carcinoma treated with surgical resection: an analysis of 13,408 patients in the Surveillance, Epidemiology, and End Results (SEER) database," Oncotarget, vol. 7, no. 48, pp. 79442-79452, 2016.

[19] A. A. Aizer, M. H. Chen, E. P. McCarthy et al., "Marital status and survival in patients with cancer," Journal of Clinical Oncology, vol. 31, no. 31, pp. 3869-3876, 2013.

[20] J. J. Jin, W. Wang, F. X. Dai et al., "Marital status and survival in patients with gastric cancer," Cancer Medicine, vol. 5, no. 8, pp. 1821-1829, 2016.

[21] Q. Li, L. Gan, L. Liang, X. Li, and S. Cai, "The influence of marital status on stage at diagnosis and survival of patients with colorectal cancer," Oncotarget, vol. 6, no. 9, pp. 7339-7347, 2015.

[22] H. Zhou, Y. Zhang, Y. Song et al., "Marital status is an independent prognostic factor for pancreatic neuroendocrine tumors patients: an analysis of the Surveillance, Epidemiology, and End Results (SEER) database," Clinics and Research in Hepatology and Gastroenterology, vol. 41, no. 4, pp. 476-486, 2017.

[23] K. A. Cronin, L. A. Ries, and B. K. Edwards, "Preface," Cancer, vol. 120, Supplement 23, pp. 3755-3757, 2014.

[24] C. Osborne, G. V. Ostir, X. Du, M. K. Peek, and J. S. Goodwin, "The influence of marital status on the stage at diagnosis, treatment, and survival of older women with breast cancer," Breast Cancer Research and Treatment, vol. 93, no. 1, pp. 41-47, 2005.

[25] K. Nayeri, G. Pitaro, and J. G. Feldman, "Marital status and stage at diagnosis in cancer," New York State Journal of Medicine, vol. 92, no. 1, pp. 8-11, 1992.

[26] N. C. Kaiser, N. Hartoonian, and J. E. Owen, "Toward a cancer-specific model of psychological distress: population data from the 2003-2005 National Health Interview Surveys," Journal of Cancer Survivorship, vol. 4, no. 4, pp. 291-302, 2010.

[27] M. Baine, F. Sahak, C. Lin, S. Chakraborty, E. Lyden, and S. K. Batra, "Marital status and survival in pancreatic cancer patients: a SEER based analysis," PLoS One, vol. 6, no. 6, article e21052, 2011.

[28] G. Goldzweig, E. Andritsch, A. Hubert et al., "Psychological distress among male patients and male spouses: what do oncologists need to know?" Annals of Oncology, vol. 21, no. 4, pp. 877-883, 2010.

[29] T. J. Iwashyna and N. A. Christakis, "Marriage, widowhood, and health-care use," Social Science \& Medicine, vol. 57, no. 11, pp. 2137-2147, 2003.

[30] W. E. Haley, "Family caregivers of elderly patients with cancer: understanding and minimizing the burden of care," The Journal of Supportive Oncology, vol. 1, 4 Supplement 2, pp. 25-29, 2003.

[31] B. Garssen and K. Goodkin, "On the role of immunological factors as mediators between psychosocial factors and cancer progression," Psychiatry Research, vol. 85, no. 1, pp. 51-61, 1999.

[32] L. S. Sklar and H. Anisman, "Stress and coping factors influence tumor growth," Science, vol. 205, no. 4405, pp. 513-515, 1979.

[33] M. Moreno-Smith, S. K. Lutgendorf, and A. K. Sood, "Impact of stress on cancer metastasis," Future Oncology, vol. 6, no. 12, pp. 1863-1881, 2010.

[34] S. M. Levy, R. B. Herberman, T. Whiteside, K. Sanzo, J. Lee, and J. Kirkwood, "Perceived social support and tumor estrogen/progesterone receptor status as predictors of natural killer cell activity in breast cancer patients," Psychosomatic Medicine, vol. 52, no. 1, pp. 73-85, 1990.

[35] B. S. McEwen, "Physiology and neurobiology of stress and adaptation: central role of the brain," Physiological Reviews, vol. 87, no. 3, pp. 873-904, 2007.

[36] S. E. Sephton, R. M. Sapolsky, H. C. Kraemer, and D. Spiegel, "Diurnal cortisol rhythm as a predictor of breast cancer survival," Journal of the National Cancer Institute, vol. 92, no. 12, pp. 994-1000, 2000.

[37] J. Cruces, C. Venero, I. Pereda-Perez, and M. Fuente, "The effect of psychological stress and social isolation on neuroimmunoendocrine communication," Current Pharmaceutical Design, vol. 20, no. 29, pp. 4608-4628, 2014.

[38] B. S. McEwen, C. A. Biron, K. W. Brunson et al., "The role of adrenocorticoids as modulators of immune function in health and disease: neural, endocrine and immune interactions," Brain Research. Brain Research Reviews, vol. 23, no. 1-2, pp. 79-133, 1997.

[39] P. Lointier, D. M. Wildrick, and B. M. Boman, "The effects of steroid hormones on a human colon cancer cell line in vitro," Anticancer Research, vol. 12, no. 4, pp. 1327-1330, 1992.

[40] S. E. Sephton, E. Lush, E. A. Dedert et al., "Diurnal cortisol rhythm as a predictor of lung cancer survival," Brain, Behavior, and Immunity, vol. 30, pp. S163-S170, 2013.

[41] N. Ferrara and T. Davis-Smyth, "The biology of vascular endothelial growth factor," Endocrine Reviews, vol. 18, no. 1, pp. 4-25, 1997.

[42] C. Burgess, V. Cornelius, S. Love, J. Graham, M. Richards, and A. Ramirez, "Depression and anxiety in women with early breast cancer: five year observational cohort study," $B M J$, vol. 330, no. 7493, pp. 702-700, 2005.

[43] L. M. Jaremka, R. Glaser, W. B. Malarkey, and J. K. KiecoltGlaser, "Marital distress prospectively predicts poorer cellular immune function," Psychoneuroendocrinology, vol. 38, no. 11, pp. 2713-2719, 2013. 


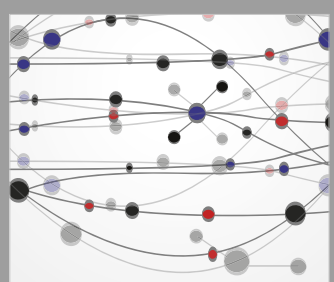

The Scientific World Journal
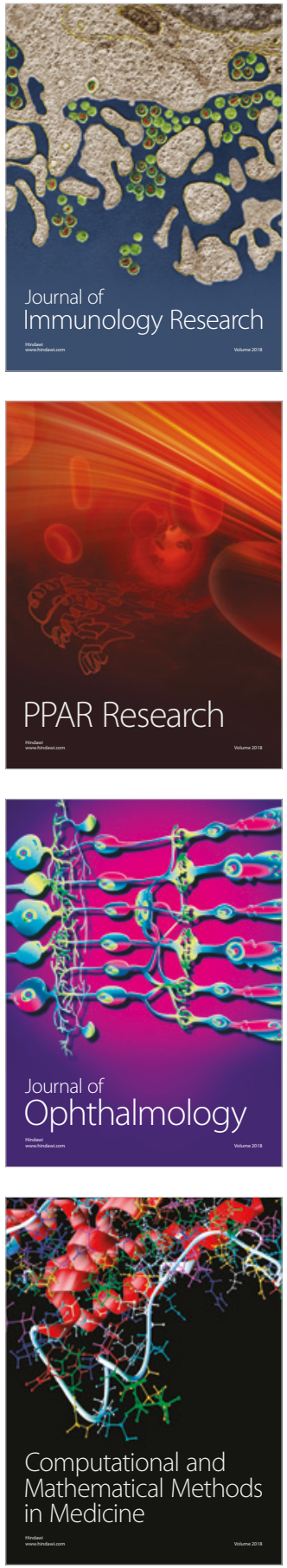

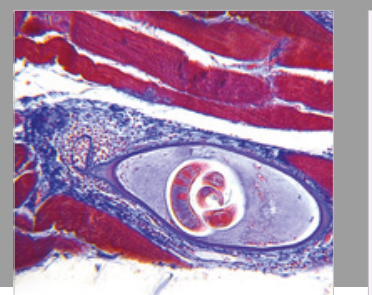

Gastroenterology Research and Practice

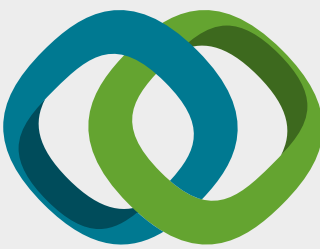

\section{Hindawi}

Submit your manuscripts at

www.hindawi.com
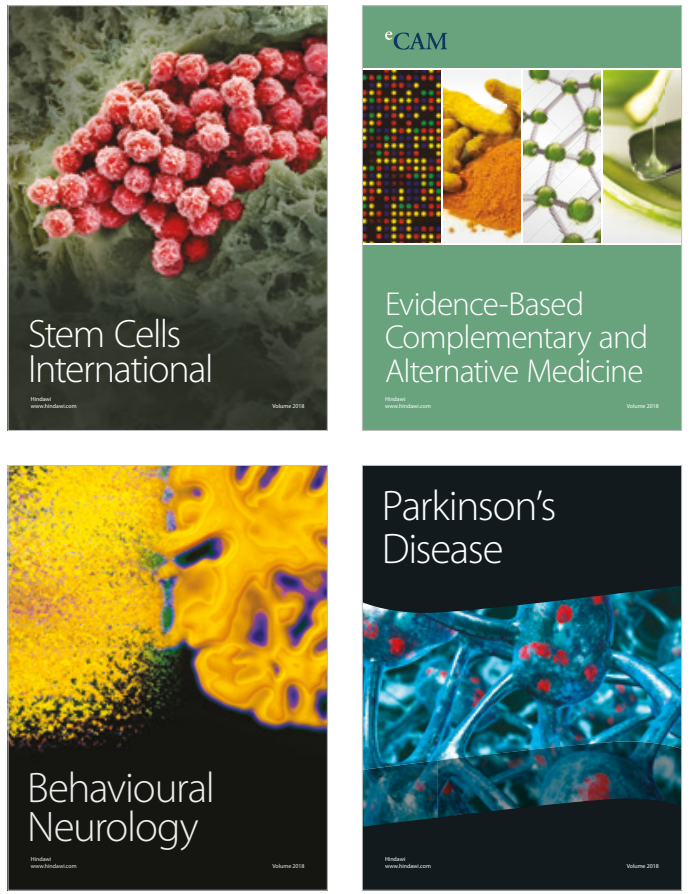

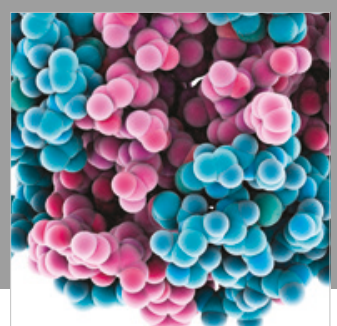

ournal of

Diabetes Research

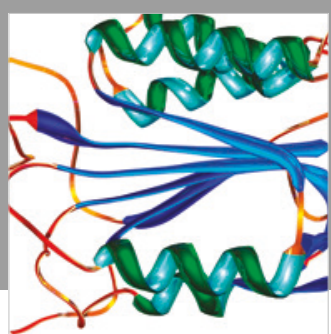

Disease Markers
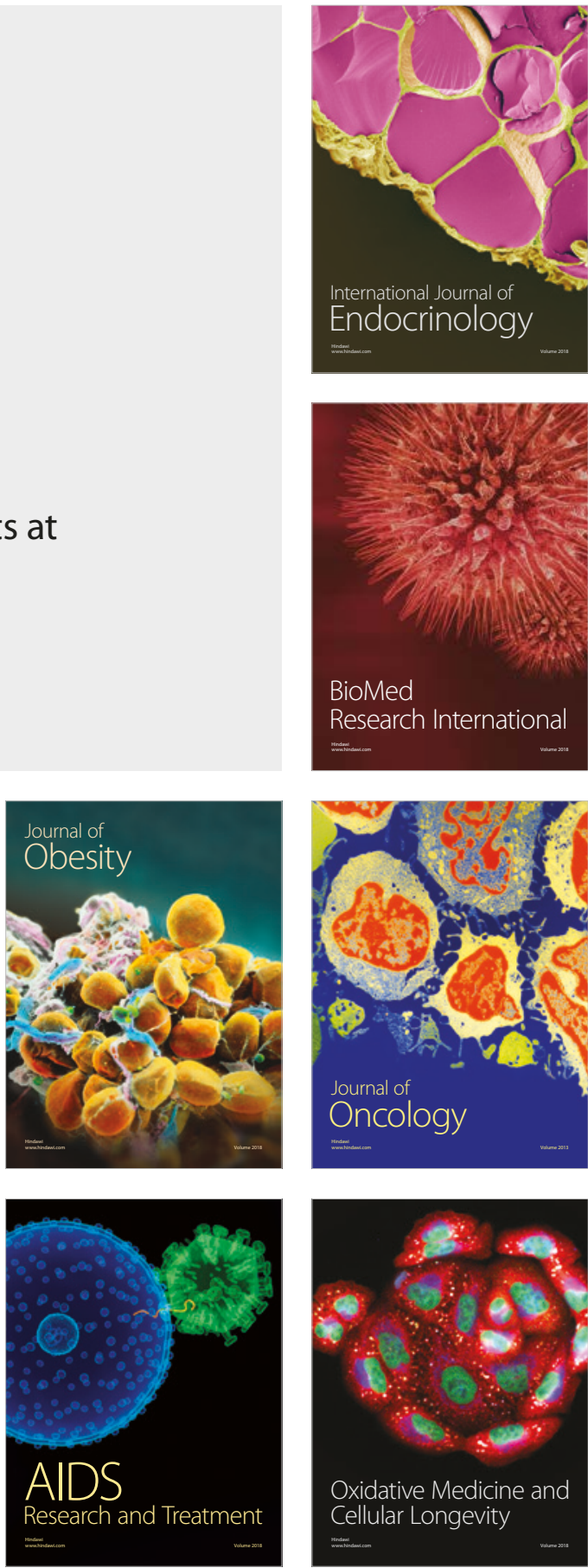